\title{
Radio-Active Iodine Ablation in Well-differentiated Thyroid Cancers
}

\section{Russell N Moule*}

Mount Vernon Cancer Centre, Northwood, Middlesex, HA6 2RN, UK

Well differentiated thyroid cancers are relatively rare and are $1 \%$ of all cancer diagnoses. The main stay of treatment is thyroidectomy (hemi- and completion), followed by radioactive-iodine abalation. Radio-active iodine $\left({ }^{131} \mathrm{I}\right)$ ablation after thyroidectomy in patients with well-differentiated thyroid cancers (Papillary, Follicular, and Mixed) is common practice although the optimal administered dose has been debated.

The management of thyroid cancer has been formalised like other cancers. The Royal College of Physicians (UK) and the American Thyroid Association have both produced guidance.

Recurrence and survival has been quoted at both 10 and 20 years depending on risk factors and the prognostic system used. The most commonly used are the AJCC TNM (Tumour, Node Metastasis) staging, and MACIS (Metastasis, Age at presentation, Completeness of surgical resection, Invasion - extra-thyroidal, and Size). Others scoring systems include AMES (Age at presentation, Metastases, Extent, Size of primary tumour), AGES (Age or presentation, Grade of Histology, Extent, Size of primary) and those from the EORTC.

Poor prognostic factors include: male, age greater than 40, tumour size greater than $5 \mathrm{~cm}$, widely invasive cancers or those with vascular invasion or poor differentiation, the presence of lymph node involvement or metastatic disease at presentation.

The use of ${ }^{131} \mathrm{I}$ ablation (3.7 GBq) aims to kill any remaining thyroid cells, as well as any potentially residual microscopic disease. The serum thyroglobulin (Tg) measurements post-treatment will be more sensitive as Tg may be produced by normal thyroid cells and thyroid cancer cells. The rationale therefore is that any rise in the $\mathrm{Tg}$ after ${ }^{131} \mathrm{I}$ ablation (providing the patient is adequately TSH suppressed on thyroxine) is due to the presence of thyroid cancer cells rather than normal thyroid cells and suggestive of persistent or recurrent disease. Also ablation reduces the risk of recurrence and prolongs survival.

The absolute indications of ${ }^{131} \mathrm{I}$ ablation include T3 disease $(>4 \mathrm{~cm})$, extra-thyroidal extension or capsular extension, lymph node involvement (with or without extra-capsular spread) or the presence of metastatic disease. Others include age greater than 45 years, tumour size 1 to $1.5 \mathrm{~cm}$. Very low risk patients for example completely excised tumours less than $1 \mathrm{~cm}$ in size will not require ablative treatment.

However in patients with lower risk disease the decision to proceed with ${ }^{131} \mathrm{I}$ ablation is not as clear cut and the use of a lower dose of ${ }^{131} \mathrm{I}$ ablation may suffice. Hackshaw, et al. in 2007 [1] undertook a systematic review into the success of low-dose ${ }^{131} \mathrm{I}$ ablation $(1.1 \mathrm{GBq}$ equivalent to $30 \mathrm{mCi})$ compared to a standard $3.7 \mathrm{Gbq}(100 \mathrm{mCi})$ ablative dose. Unfortunately the data did not provide any robust conclusions.

The HiLO study [2] has specifically tried to address this issue. This study compared 1.1 GBq and 3.7 GBq ablative doses as well as the use of recombinantTSH (rTSH). Patients with T1 to T3 N0/1 M0 well differentiated thyroid cancer as well as Hurthle cell cancer we randomised to $1.1 \mathrm{GBq}$ and $3.7 \mathrm{GBq}$ radio-active iodine ablation and either rTSH $(0.9 \mathrm{mg}$ day 1 and 2 pre-radioactive iodine) or standard withdrawal of thyroxine or liothyronine.
Out of the 438 patients that were recruited to the study 421 patients were evaluated. There was no significant difference in the ablation success between the two doses of radioactive iodine ( $85.0 \%$ vs. $88.9 \%$ ). This was also the case for the use of rTSH. Nine and a half percent of patients who received $1.1 \mathrm{GBq}$ required a further re-treatment compared to $4.1 \%$ in the $3.7 \mathrm{GBq}$ group $(\mathrm{p}=0.02)$ However there was a significant reduction in the number of days admission. Patients who received $1.1 \mathrm{GBq}$ were more likely to spend less time in hospital with $39.6 \%$ compared to $7.1 \%$ requiring only one day admission $(\mathrm{p}<0.001)$. Less side effects were also experienced in the $1.1 \mathrm{GBq}$ group ( $21 \%$ vs. $33 \% \mathrm{p}<0.007)$.

This study has provided important information as there was no difference in the ablation success rate between the low dose and high dose groups and similarly the use of rTSH did not have a significant impact on this rate.

As far as quality of life is concerned the use of $1.1 \mathrm{GBq}$ radio-active iodine abaltion has significant advantages as the radiation protection issues surrounding administration are less and patients spend less time isolated and away from family life. For units that have pressure on treatment room usage $1.1 \mathrm{GBq}$ in this group of patients allows a greater throughput and less treatment delays.

Following this study the same group attempting to answer the next question of whether radio-active iodine ablation is actually required in low-risk patients. This is being addressed through the IoN (Iodine or Not in low risk differentiated thyroid cancer) study.

There is no disadvantage with the use of low dose $1.1 \mathrm{GBq}$ radioactive iodine ablation compared to $3.7 \mathrm{GBq}$ in patients with low risk well differentiated thyroid cancers. The HiLo [3] study is a great step forward in the management of the patients and IoN will provide further valuable information over the coming years.

\section{References}

1. Hackshaw A, Harmer C, Mallick U, Haq M, Franklyn JA (2007). ${ }^{131}$ I activity for remnant ablation in patients with differentiated thyroid cancer: a systematic review. J Clin Endocrinol Metab. 92: 28-38.

2. Mallick U, Harmer C, Yap B, Wadsley J, Clarke S, et al. (2012). Ablation with low-dose radioiodine and thyrotrophin alpha in thyroid cancer. $\mathrm{N}$ Engl J Med 366: 1674-1685.

3. Mallick U, Harmer C, Hackshaw A, Moss L, IoN Trial Management Group (2012). lodine or not (IoN) for low-risk differentiated thyroid cancer: the next Uk National Cancer Research Network randomised trial following HiLo. Clin Oncol (R Coll Radiol) 24: 159-161.

*Corresponding author: Russell $\mathrm{N}$ Moule, Mount Vernon Cancer Centre, Northwood, Middlesex, HA6 2RN, UK; E-mail: russell.moule@nhs.net

Received July 19, 2012; Accepted July 20, 2012; Published July 23, 2012

Citation: Moule RN (2012) Radio-Active lodine Ablation in Well-differentiated Thyroid Cancers. J Nucl Med Radiat Ther 3:e103. doi:10.4172/21559619.1000e103

Copyright: (c) 2012 Moule RN. This is an open-access article distributed under the terms of the Creative Commons Attribution License, which permits unrestricted use, distribution, and reproduction in any medium, provided the original author and source are credited. 